\title{
Trait Association and Path Analysis of Tef [Eragrostis tef (Zucc.) Trotter] Genotypes under Acid Soil Stress
}

\author{
Misgana Merga* \\ Ethiopian Institute of Agricultural Research, Assosa Agricultural Research Center \\ PO box 256, Assosa, Ethiopia \\ Hussein Mohammed \\ Department of Plant and Horticultural Science, Hawassa University, Hawassa, Ethiopia \\ Kebebew Assefa \\ Ethiopian Institute of Agricultural Research, Debre-Zeit Agricultural Research Center, Debre-Zeit, Ethiopia
}

\begin{abstract}
The research is financed by Ethiopian Institute of Agricultural Research (Sponsoring information)
Abstract

Correlation and path analysis is the most important analysis that provides a better understanding of the magnitude, direction and actual contribution of traits on yield that are very useful in the selection of genotypes from the different genetic populations. Thus, the current study consists of forty-nine tef genotypes were evaluated under with and without lime treated soils in the lat house of Assosa Agricultural Research Centre during 2017 to study the association between yield and yield component; and identify the most influential traits under both soil conditions. At both phenotypic and genotypic levels grain yield was significantly $(\mathrm{p} \leq 0.01)$ and positively correlated with harvest index $(r>0.90)$, yield of primary panicle $(r>0.50)$, panicle weight $(r>0.40)$ and negatively correlated with days to maturity $(\mathrm{r}<-0.50)$ under both soil environments and with days to heading $(\mathrm{r}<-0.30)$ only under acid soil. This indicates the improvement of these traits would contribute to the higher grain yield of tef. Path coefficient analysis revealed shoot biomass yield and harvest index were the most influential traits that determined grain yield under both soil environments. Therefore, the focus should be given for these traits during the selection of high yielding genotypes of tef.
\end{abstract}

Keywords: correlation, direct effect, grain yield, indirect effect

DOI: $10.7176 /$ ALST/86-03

Publication date:March $31^{\text {st }} 2021$

\section{INTRODUCTION}

Tef is a cereal crop that widely cultivated throughout Ethiopia as a staple crop. It is highly nutritious, excellent in amino acid composition and its lysine content is higher than that of all cereals except rice and oats (Melak-Hail, 1966, Seyfu, 1997). The other advantage of tef is free of a protein known as gluten which is found in wheat, barley, and rice, which can cause celiac disease by aberrant T-cell (Spaenij Dekking et al., 2005) and thus, it makes more suitable for the people.

Tef grows in a wide range of environmental conditions and tolerant to drought, waterlogging and disease (Seyfu, 1997). It is also well adapted to the heavy and well-drained clay soil (Vertisol) areas of the Ethiopian highlands. Tef has a short growing season with rainfall needs of 450-550 mm, and a temperature range of 10$27^{\circ} \mathrm{C}$ during its growing season (Stallknecht, 1997, Roseberg et al., 2005). Tef covers about 3 million hectares of land and widely cultivated in Oromia, Amhara, Tigray, SNNPR and Benishangul Gumuz regions of Ethiopia. The average productivity of tef is about 1.75 tons hectare ${ }^{-1}$ at the country level (CSA, 2018). It is still low and not sufficiently fulfills the demands in the country.

Grain yield is a complex trait and can be partitioned into different components like number of fertile tillers, form of panicles, number of florets per panicle, and seed weight. It is influenced directly or indirectly by several other agronomic characters like plant height, leaf area, dry matter yield, heading date, lodging and proneness to shattering (Eswaran et al., 1997). Correlation studies provide a better understanding of yield components which helps plant breeder's during selection (Robertson, 1959). It is measured as genotypic and phenotypic coefficients correlation. The association between two characters can directly be observed as phenotypic correlation, while genotypic correlation expresses the extent to which two traits are genetically associated. Both genotypic and phenotypic correlations among and between pairs of agronomic traits provide scope for indirect selection in a crop breeding program (Pavan et al., 2011).

However, correlation does not provide information about the direct and indirect effects of characters. Path coefficient analysis is used to partitioning the correlation coefficients into direct and indirect effects and more clearly indicate the contribution of a character on the grain yield (Dewey and Lu, 1959). Knowing the relation of yield components under different stress conditions is very useful in the selection of genotypes from the different genetic populations. Therefore, this investigation was conducted to study the association between yield and yield 
component traits and identify contributing traits that can be used as a direct and indirect selection for high yield under two soil acidity conditions.

\section{MATERIALS AND METHODS}

The experiment was conducted in lat house at Assosa Agricultural Research Center (AsARC) in Benishangul Gumuz Region, Ethiopia. For this study, a total of 49 tef genotypes were used. These include 44 germplasms collected from different areas of Ethiopia, 4 improved varieties (Ambo Toke, Etsuib, Kora and Quncho), and a local check. All of the planting materials except the check were kindly provided by Debre Zeit Agricultural Research Center (DZARC).

The acid soil $(\mathrm{pH}=4.97)$ collected from the field of Assosa Agricultural Research Centre was used for the pot experiment. This soil was grouped into two: - one used as it is (acidic soil) without application of lime and the other was used with lime treatment. The lime requirement in ton hectare ${ }^{-1}$ was obtained based on the results of bulk density $\left(1.4 \mathrm{mg} \mathrm{m}^{-3}\right)$ and exchangeable acidity $\left(3.86 \mathrm{Cmol}^{-\mathrm{kg}^{-1}}\right)$ of the soil, then calculated by using the formula of Bruce (1997). Accordingly, to raise the $\mathrm{pH}$ value near to 6.0, a $2 \mathrm{~kg}$ of acid soil was treated with 4.71 $\mathrm{g}$ of fine particles of quicklime $(\mathrm{CaO})$ which is equivalent to $4 \mathrm{tha}^{-1}$ of lime. It was thoroughly mixed on a clean tray and then filled into the plastic pot which has $14 \mathrm{~cm}$ top and $10.2 \mathrm{~cm}$ bottom diameter with $17.4 \mathrm{~cm}$ height. All pots were incubated for two weeks before planting in the lat house. After two weeks, twenty seeds of each tef genotype were planted per pot on September 20, 2017, and then thinned to five plants per pot 30-35 days after planting. Each genotype was replicated in three pots and the 147 pots of one experiment were arranged in Completely Randomized Design (CRD) in the lat house of Assosa Agricultural Research Centre. There were two such experiments laid side by side: one on lime treated soil and another on un-lime treated soil. Fertilizer rate of $46 \mathrm{~kg} \mathrm{ha}^{-1} \mathrm{P}_{2} \mathrm{O}_{5}$ in the form of NPS was applied at the time of sowing and $23 \mathrm{~kg} \mathrm{ha}^{-1} \mathrm{~N}_{2}$ in the form of Urea was applied 30-35 days after planting. The pots were irrigated uniformly by using a water cap and frequent hand weeding was done.

Data were collected from the pot and individual plant basis. Pot basis data were days to heading (DTH), days to maturity (DTM), grain filling period (GFP), grain yield/pot (GY), shoot biomass (SBM) and harvest index (HI). Whereas data like plant height (PH), panicle length (PL), culm length (CL), peduncle length (PDUL), number of total tillers per plant (TT), number of fertile tillers per plant (FT), number of primary panicle branches (PPB), first basal culm internodes diameter (FBID), second basal culm internode diameter (SBID), panicle weight (PW) and grain yield of primary panicle (YPP) were recorded from individual plants per pot and the average was used for analyses. Phenotypic and genotypic correlation coefficients based on the mean data of 49 tef genotypes from corresponding variance and covariance components were estimated using the standard procedure suggested by Johanson et al. (1955). The coefficient of correlations at the genotypic level was tested for their significance using the formula described by Robertson (1959). The calculated " $t$ " value was compared with the tabulated " $t$ " value at (n-2) degree of freedom at 5\% level of significance. Path coefficient analysis was performed using the phenotypic and genotypic correlation coefficients to know the direct and indirect effect of yield components on grain yield using the formula of Dewey and $\mathrm{Lu}(1959)$ by considering grain yield pot $^{-1}$ as a dependent variable. The residual effect, which determines how best the causal factors account for the variability of the dependent factor, was calculated following the formula proposed by Dewey and Lu (1959).

\section{RESULTS AND DISCUSSIONS}

\subsection{Association of Traits}

Phenotypic and genotypic correlation coefficients between all possible pairs of 17 traits of 49 tef genotypes tested under acidic and lime-treated soil conditions are presented in Tables 1 and 2. For both soil environments, the genotypic correlation coefficients were higher in magnitude than the phenotypic correlation coefficients for almost all characters indicating the presence of inherent genetic relationships among various characters, although the effects of the environment also observed on the traits.

At the level of both phenotypic $\left(r_{p}\right)$ and genotypic $\left(r_{g}\right)$ correlation coefficients, grain yield under acid soil stress condition showed significant $(\mathrm{p} \leq 0.01)$ positive correlation with harvest index $\left(r_{g}=r_{p}=0.93\right)$, grain yield of primary panicle $\left(r_{p}=0.6, r_{g}=0.52\right)$, panicle weight $\left(r_{p}=0.55, r_{g}=0.59\right)$, shoot biomass $\left(r_{p}=0.43, r_{g}=0.6\right)$ and primary panicle branches $\left(\mathrm{r}_{\mathrm{p}}=0.26\right)$. On the other hand, grain yield was negatively associated with days to heading $\left(r_{p}=-0.3, r_{g}=-0.32\right)$, and days to maturity $\left(r_{p}=-0.4, r_{g}=-0.57\right)$.

Under lime treated soil, grain yield showed significant $(<0.01)$ positive correlation with harvest index $\left(r_{p}=\right.$ $\left.0.93, r_{g}=0.96\right)$, yield of primary panicle $\left(r_{p}=0.57, r_{g}=0.54\right)$, panicle weight $\left(r_{p}=0.41, r_{g}=0.39\right)$ and, shoot biomass (only for $r_{p}=0.27$ ), while it was negatively correlated with days to maturity $\left(r_{p}=-0.44, r_{g}=-0.51\right)$. A positive correlation of grain yield with these traits implies that selection based on these traits could be more efficient to maximize the grain yield of tef genotypes under these soil conditions.

Similar to the present results, Wondewosen et al. (2012) reported a significant positive correlation of grain yield with harvest index, shoot biomass and yield per panicle in tef genotypes tested under drought and non- 
drought stress conditions. Likewise, Mizan et al. (2017) also reported a significant positive genotypic correlation of grain yield with shoot biomass, harvest index and grain yield of the primary panicle.

The negative correlation of characters is the indicative inverse relationship to each other that when one character increased the other one would be decreased and vice versa. The negative association of grain yield with days to maturity indicates grain yield is inversely related to the period of maturity, means grain yield might be reduced as the maturity period increased. In line with the present results, the negative correlation of grain yield with days to maturity was noted by (Kebebew et al., 2002, Plaza-Wüthrich et al., 2013, Haftamu, 2015, Chekole et al., 2016). Wondewosen et al. (2012) also reported a negative correlation of grain yield with grain filling period indicating the possibility of using rapid maturity to escape the effects of drought. This might also be true for soil acidity stress environment.

On the other hand, the yield-related character grain yield of primary panicle was strongly correlated with all characters except days to heading, days to maturity, shoot biomass and primary panicle branches under acid soil and only days to maturity and shoot biomass under lime treated soil. At the level of phenotypic correlation coefficients, shoot biomass was positively associated with the number of total tillers, peduncle length, panicle weight, grain yield and second basal culm internode diameter and negatively correlated with grain filling period. It also positively correlated with a majority of the traits and negatively correlated with only days to maturity and grain filling period at the level of the genotypic correlation coefficient under acidic soil. In contrast, under lime treated soil at both levels of the correlation coefficient, shoot biomass showed no significant association with all of the traits except negative correlation with only days to heading and maturity at the genotypic level. This suggested that shoot biomass is also relatively important to be used as one of the selection criteria in acid soil stress.

Harvest index was correlated positively with panicle weight, the yield of primary panicle and grain yield pot ${ }^{-}$ ${ }^{1}$, while it was negatively correlated with days to heading and maturity under both soil conditions. The negative correlation of harvest index with phenological traits indicated that earliness in heading and maturity results in higher partitioning of assimilates toward the economic sink and thereby increasing yield under acid stress condition because grain yield was positively correlated with harvest index. This result agreed with the reports of (Wondewosen et al., 2012, Chekole et al., 2016).

Positive and strong associations were observed among plant height, panicle, culm, and peduncle length, diameters of the two basal culm internodes, and primary panicle branches. They were also negatively correlated with grain filling period, the number of total and fertile tillers per plant at both phenotypic and genotypic correlation coefficient under both soil conditions. The negative correlation of both tillers with other growth characters revealed that increment in the number of tillers per plant reduces plant height, panicle length, culm length, and peduncle length and the thickness of two basal culm internodes. Besides, the two lodging-related traits, diameters of the first and second basal culm internodes, were significantly and positively correlated with growth traits such as plant height, panicle, culm, and peduncle length at both phenotypic and genotypic coefficient levels under both soil conditions. This implies thicker culm diameter results an increment in growth characters. This result is partially agree with the previous studies of Kebebew et al. (2002) and Plaza-Wüthrich et al. (2013).

Table 1. Phenotypic (above diagonal) and Genotypic (below diagonal) correlation coefficients of 17 traits studied under acid (un-lime) soil

\begin{tabular}{|c|c|c|c|c|c|c|c|c|c|c|c|c|c|c|c|c|c|}
\hline Variable & DTH & DTM & GFP & PH & PL & CL & PDUL & TT & FT & PW & YPP & SBM & GY & HI & FBID & SBID & PPB \\
\hline DTH & 1 & $0.5^{* *}$ & $-0.75^{\text {***}}$ & $0.54^{* \star}$ & $0.35^{*}$ & $0.57^{\star \star}$ & $0.52^{* \star}$ & -0.13 & -0.2 & 0.26 & 0.22 & 0.12 & $-0.3^{*}$ & $-0.38^{* * *}$ & $0.32^{*}$ & $0.35^{*}$ & $0.56^{* \star}$ \\
\hline DTM & $0.56^{\star \star}$ & 1 & 0.16 & $0.36^{\star *}$ & $0.3^{*}$ & $0.3^{*}$ & 0.11 & -0.16 & -0.18 & -0.1 & -0.034 & -0.25 & $-0.4^{* *}$ & $-0.4^{* *}$ & 0.02 & 0.17 & $0.49^{* *}$ \\
\hline GFP & $-0.77^{* *}$ & 0.1 & 1 & $-0.36^{* *}$ & -0.17 & $-0.42^{* *}$ & $-0.5^{\text {** }}$ & 0.03 & 0.11 & $-0.38^{\star *}$ & $-0.28^{*}$ & $-0.34^{*}$ & 0.004 & 0.12 & $-0.36^{* *}$ & $-0.28^{\star}$ & -0.27 \\
\hline PH & $0.58^{* *}$ & $0.39^{* \star}$ & $-0.39 * *$ & 1 & $0.83^{* \star}$ & $0.92^{\star *}$ & $0.74^{\star \star}$ & $-0.53^{\star *}$ & $-0.61^{* *}$ & $0.52^{\star \star *}$ & $0.43^{* *}$ & 0.1 & -0.12 & -0.2 & $0.5^{\star \star}$ & $0.41^{\star \star}$ & $0.73^{\star *}$ \\
\hline PL & $0.39^{* *}$ & $0.34^{\star \star}$ & -0.19 & $0.86^{* *}$ & 1 & $0.54^{* \star}$ & $0.55^{\star \star}$ & $-0.53^{\text {** }}$ & -0.58 ** & $0.52^{\star *}$ & $0.36^{* \star}$ & 0.07 & -0.055 & -0.12 & $0.48^{* \star}$ & $0.41^{* *}$ & $0.67^{* \star}$ \\
\hline CL & $0.63^{* \star *}$ & $0.36^{* \star}$ & $-0.48^{\star \star *}$ & $0.92^{* *}$ & $0.59^{* \star}$ & 1 & $0.73^{\star \star}$ & $-0.43^{* \star}$ & $-0.51^{\star \star *}$ & $0.42^{\star \star *}$ & $0.39^{* \star}$ & 0.11 & -0.14 & -0.22 & $0.41^{\star \star}$ & $0.33^{*}$ & $0.62^{* *}$ \\
\hline PDUL & $0.62^{* \star *}$ & 0.09 & $-0.67^{* *}$ & $0.81^{* *}$ & $0.59^{* \star *}$ & $0.82^{* *}$ & 1 & $-0.38^{* *}$ & $-0.45^{\star *}$ & $0.58^{* *}$ & $0.45^{* \star}$ & $0.32^{*}$ & 0.17 & 0.06 & $0.47^{* \star}$ & $0.40^{* *}$ & $0.55^{\star \star}$ \\
\hline TT & -0.12 & -0.21 & 0.04 & $-0.65^{\text {** }}$ & $-0.62 * *$ & $-0.55^{\text {** }}$ & $-0.49^{* *}$ & 1 & $0.96^{* *}$ & $-0.49^{* *}$ & $-0.51^{\star \star *}$ & $0.28^{*}$ & -0.13 & -0.23 & $-0.55^{* *}$ & -0.49 ** & $-0.45^{\star \star}$ \\
\hline FT & -0.26 & $-0.23^{*}$ & 0.14 & $-0.73^{* *}$ & $-0.69 * *$ & $-0.63^{* *}$ & $-0.57^{* \star}$ & $0.98^{\star \star}$ & 1 & $-0.52 * *$ & $-0.5^{* *}$ & 0.24 & -0.06 & -0.14 & $-0.56^{\star *}$ & $-0.5^{\text {** }}$ & $-0.56^{\star \star}$ \\
\hline PW & $0.3^{* *}$ & -0.14 & $-0.47^{* *}$ & $0.56^{* *}$ & $0.56^{* *}$ & $0.45^{* *}$ & $0.66^{\star \star}$ & $-0.61^{* *}$ & $-0.64^{* *}$ & 1 & $0.85^{* *}$ & $0.38^{* *}$ & $0.55^{\star \star}$ & $0.44^{\star \star}$ & $0.51^{* *}$ & $0.46^{* *}$ & $0.34^{\star}$ \\
\hline YPP & 0.23 & -0.05 & $-0.37^{\star \star}$ & $0.45^{\star \star}$ & $0.39^{* *}$ & $0.41^{\star \star}$ & $0.51^{* \star}$ & $-0.56^{\star \star}$ & $-0.54^{* \star}$ & $0.94^{* \star}$ & 1 & 0.21 & $0.6^{* \star}$ & $0.56^{* \star}$ & $0.33^{*}$ & $0.31^{\star}$ & 0.23 \\
\hline SBM & 0.14 & $-0.34^{\text {** }}$ & $-0.44^{\star *}$ & 0.04 & 0.03 & 0.04 & $0.39^{* *}$ & $0.34^{* *}$ & $0.29^{*}$ & $0.41^{* *}$ & $0.27^{*}$ & 1 & $0.43^{\star \star \star}$ & 0.08 & 0.24 & $0.33^{*}$ & 0.007 \\
\hline GY & $-0.32^{* *}$ & $-0.57^{\text {** }}$ & -0.05 & -0.19 & -0.09 & -0.23 & 0.098 & -0.12 & -0.06 & $0.59^{* *}$ & $0.52^{\star *}$ & $0.6^{* *}$ & 1 & $0.93^{* *}$ & 0.07 & 0.17 & $-0.26^{*}$ \\
\hline HI & $-0.45^{* *}$ & $-0.56^{* *}$ & 0.1 & $-0.29 *$ & -0.17 & $-0.32^{*}$ & -0.05 & -0.26 & -0.15 & $0.49^{* *}$ & $0.47^{* \star}$ & 0.28 & $0.93^{* *}$ & 1 & -0.027 & 0.03 & $-0.3^{*}$ \\
\hline FBID & $0.36^{* *}$ & 0.04 & $-0.4^{\star *}$ & $0.58^{* *}$ & $0.57^{* \star}$ & $0.48^{* *}$ & $0.58^{* *}$ & $-0.74^{* *}$ & $-0.76^{* *}$ & $0.65^{* *}$ & $0.47^{* *}$ & 0.26 & 0.1 & -0.05 & 1 & $0.83^{* *}$ & $0.45^{* \star}$ \\
\hline SBID & $0.44^{* \star}$ & $0.26^{*}$ & $-0.33^{* *}$ & $0.53^{* \star}$ & $0.55^{* *}$ & $0.42^{* *}$ & $0.53^{* \star}$ & $-0.7^{\star \star}$ & $-0.77^{* *}$ & $0.67^{* *}$ & $0.48^{* *}$ & $0.44^{* \star}$ & 0.19 & 0.03 & $0.95^{\star \star}$ & 1 & $0.4^{* \star}$ \\
\hline PPB & $0.63^{* \star}$ & $0.58^{\star \star}$ & $-0.3^{\star \star}$ & $0.81^{\star \star}$ & $0.72^{\star \star}$ & $0.72^{\star \star}$ & $0.61^{* *}$ & $-0.58^{\star *}$ & $-0.73^{* *}$ & $0.4^{\star \star}$ & $0.28^{\star}$ & -0.02 & $-0.37^{\star \star}$ & $-0.47^{* *}$ & $0.54^{\star \star *}$ & $0.53^{\star \star}$ & \\
\hline
\end{tabular}

*, **: significant at 5 and $1 \%$ of probability level, respectively, DTH: days to heading, DTM: days to maturity, GFP: grain filling period, PH: plant height, PL: panicle length, CL: culm length, PDUL: peduncle length, TT: number of total tillers/plant, FT: number of fertile tillers/plant, PW: panicle weight, YPP: yield of primary panicle, SBM: shoot biomass, GY: grain yield pot $^{-1}$, HI: harvest index, FBID: first basal culm internode diameter, SBID: second basal culm internode diameter, PPB: primary panicle branches. 
Table 2. Phenotypic (above diagonal) and Genotypic (below diagonal) correlation coefficients of genotypes tested under lime treated soil

\begin{tabular}{|c|c|c|c|c|c|c|c|c|c|c|c|c|c|c|c|c|c|}
\hline Variable & DTH & DTM & GPF & PH & PL & CL & PDUL & TT & FT & PW & GYPP & SBM & GY & HI & FBI & SBI & PB \\
\hline DTH & 1 & $0.57^{7 *}$ & $-0.72^{* *}$ & $10.54^{\star \star}$ & $0.35^{* *}$ & $0.58 * \star$ & $0.45^{* *}$ & -0.18 & $-0.28^{*}$ & 0.22 & $0.34^{\star \star}$ & -0.21 & -0.25 & -0.18 & $0.36^{*}$ & $0.35^{*}$ & $0.27^{\star}$ \\
\hline DTM & $0.6^{* \star}$ & 1 & 0.15 & $0.31^{*}$ & 0.25 & $0.3^{*}$ & 0.19 & -0.014 & -0.11 & 0.05 & 0.076 & -0.21 & $-0.44^{\star \star}$ & $-0.39 *$ & 0.16 & 0.2 & $0.28 *$ \\
\hline GPF & $-0.73^{* \star}$ & 0.1 & 1 & $-0.39 * *$ & -0.2 & $-0.44^{*}$ & $-0.37 *$ & 0.21 & 0.25 & -0.21 & $-0.34^{* \star}$ & 0.07 & 0.08 & 0.11 & $-0.29 *$ & -0.26 & -0.09 \\
\hline PH & $0.59 * *$ & $0.36^{\star *}$ & $-0.46^{* *}$ & 1 & $0.84^{* \star}$ & $0.95^{* *}$ & $0.69 * \star$ & $-0.57^{* \star}$ & $-0.66^{\star \star}$ & $0.58^{\star *}$ & $0.58^{\star \star}$ & 0.06 & -0.08 & -0.12 & $0.52^{\star *}$ & $0.5^{* \star}$ & $0.5^{\star \star}$ \\
\hline PL & $0.38^{* *}$ & 0.29 & -0.22 & $0.86 * *$ & 1 & $0.59 * \star$ & $0.52^{\star *}$ & $-0.59^{* *}$ & $-0.65^{\text {** }}$ & $0.47^{* *}$ & $0.4^{* *}$ & 0.085 & -0.18 & -0.18 & $0.40^{* *}$ & $0.40^{* *}$ & $0.46^{* *}$ \\
\hline $\mathrm{CL}$ & $0.64^{* *}$ & $0.32^{*}$ & $-0.53^{* k}$ & $0.95^{* *}$ & $0.66^{* *}$ & 1 & $0.69 * *$ & $-0.46^{* \star}$ & $-0.57^{* *}$ & $0.56^{* *}$ & $0.6^{* *}$ & 0.04 & -0.01 & -0.04 & $0.5^{* \star}$ & $0.48^{* *}$ & $0.46^{\star *}$ \\
\hline PDUL & $0.48^{* \star}$ & 0.21 & $-0.42^{\star \star *}$ & $0.75^{\star *}$ & $0.59 * *$ & $0.75^{\star \star}$ & 1 & $-0.51^{\star \star}$ & $-0.61^{\star *}$ & $0.57 \star \star$ & $0.65^{\star \star *}$ & 0.14 & 0.18 & 0.11 & $0.48 * \star$ & $0.44^{\star *}$ & $0.43^{* *}$ \\
\hline TT & -0.25 & -0.06 & 0.26 & $-0.66^{* *}$ & $-0.69^{* *}$ & $-0.55^{* *}$ & $-0.66^{* *}$ & 1 & $0.98 * *$ & $-0.7^{* *}$ & $-0.62^{* *}$ & 0.1 & -0.22 & -0.27 * & $-0.65^{* *}$ & $-0.56^{* *}$ & $-0.66^{* \star}$ \\
\hline FT & $-0.37^{* \star}$ & -0.18 & $0.31^{*}$ & $-0.78^{\star \star}$ & $-0.78^{* *}$ & $-0.68^{* *}$ & $-0.79 * \star$ & $0.99 * \star$ & 1 & $-0.72^{\star \star}$ & $-0.66^{* \star}$ & 0.11 & -0.18 & -0.22 & $-0.7^{* \star}$ & $-0.61^{* \star}$ & $-0.7^{\star \star}$ \\
\hline PW & 0.22 & 0.05 & -0.23 & $0.62^{\star *}$ & $0.53^{* *}$ & $0.6^{* *}$ & $0.65^{* *}$ & $-0.86^{* *}$ & $-0.9 * \star$ & 1 & $0.86^{* *}$ & 0.18 & $0.41^{* *}$ & $0.36^{* *}$ & $0.55^{* *}$ & $0.44^{* *}$ & $0.68^{* *}$ \\
\hline GYPP & $0.37^{* \star}$ & 0.07 & $-0.4^{* \star}$ & $0.61^{* *}$ & $0.43^{* *}$ & $0.64^{\star \star}$ & $0.74^{\star \star}$ & $-0.78^{* \star}$ & $-0.85^{\star *}$ & $0.89 * *$ & 1 & 0.086 & $0.57 * \star$ & $0.56^{* \star}$ & $0.48 * \star$ & $0.42^{\star \star *}$ & $0.57^{\star *}$ \\
\hline SBM & $-0.33^{*}$ & $-0.32^{*}$ & 0.13 & -0.01 & 0.02 & 0.03 & 0.14 & 0.19 & 0.19 & 0.02 & -0.17 & 1 & $0.27^{*}$ & -0.081 & -0.19 & -0.1 & -0.07 \\
\hline GY & -0.28 & $-0.51^{* *}$ & -0.09 & -0.14 & -0.24 & -0.06 & 0.2 & $-0.33^{* *}$ & $-0.3^{*}$ & $0.39 * *$ & $0.54^{* *}$ & 0.05 & 1 & $0.93^{* *}$ & -0.05 & -0.06 & 0.03 \\
\hline HI & -0.18 & $-0.41^{* *}$ & -0.13 & -0.15 & -0.27 & 0.07 & 0.13 & $-0.37^{\star \star}$ & $-0.33^{\star}$ & $0.37^{* \star}$ & $0.57 * \star$ & -0.22 & $0.96 * \star$ & 1 & 0.04 & -0.01 & 0.06 \\
\hline FBI & $0.43 * \star$ & 0.22 & $-0.35^{* *}$ & $0.58 * \star$ & $0.47 * \star$ & $0.57 * \star$ & $0.56 * *$ & $-0.77^{* *}$ & $-0.82^{* *}$ & $0.67 * *$ & $0.6^{* \star}$ & -0.28 & -0.04 & 0.05 & 1 & $0.85^{\star *}$ & $0.67^{* *}$ \\
\hline SBI & $0.44^{\star \star}$ & 0.26 & $-0.33^{*}$ & $0.64^{\star \star *}$ & $0.56^{* *}$ & $0.61^{\star *}$ & $0.55^{\star *}$ & $-0.73^{* \star}$ & $-0.78^{* \star}$ & $0.62^{\star \star *}$ & $0.58 * \star$ & -0.18 & -0.05 & -0.003 & $0.96^{\star *}$ & 1 & $0.49 * *$ \\
\hline PB & $0.34^{\star \star *}$ & $0.37^{* \star \star *}$ & -0.12 & $0.54^{\star \star}$ & $0.46^{* *}$ & $0.53^{\star \star \star}$ & $0.5^{\star \star *}$ & $-0.79^{\star \star *}$ & $-0.85^{\star \star}$ & $0.84^{\star \star}$ & $0.69 * \star$ & -0.12 & 0.01 & 0.07 & $0.75^{\star \star}$ & $0.66^{\star \star}$ & 1 \\
\hline
\end{tabular}

*, **: significant at 5 and $1 \%$ of probability level, respectively, DTH: days to heading, DTM: days to maturity, GFP: grain filling period, PH: plant height, PL: panicle length, CL: culm length, PDUL: peduncle length, TT: number of total tillers/plant, FT: number of fertile tillers/plant, PW: panicle weight, YPP: yield of primary panicle, SBM: shoot biomass, GY: grain yield pot-1, HI: harvest index, FBID: first basal culm internode diameter, SBID: second basal culm internode diameter, PPB: primary panicle branche

\subsection{Path Coefficient Analysis}

Path coefficient analysis measures the direct influence of one variable upon the other and permits the separation of coefficients into components of direct and indirect effects. The direct and indirect effect at a phenotypic level under acid soil is presented in Table 3. It was carried out using five traits (days to heading and maturity, plant height, shoot biomass and harvest index) which explained $99.2 \%$ of the variability in grain yield.

The highest direct effect (0.91) is that of harvest index, the next highest (0.36) being that of shoot biomass. The other three traits exerted almost equal in magnitude direct effect on grain yield pot $^{-1}$; days to maturity and plant height having a positive direct effect while days to heading had a negative direct effect, although all three had a negative correlation with grain yield. Selecting early heading, relatively taller and late-maturing plants with high shoot biomass and high harvest index will lead to the identification of genotypes with high grain yield under acid soil condition. However, the indirect effect of DTH, DTM, and PH through HI was negative (-0.19 to -0.37$)$ and caution should be taken not to select too tall genotypes which mature too late, since this may lead to a reduction of yield through reduction of harvest index. DTH, DTM, and PH had a negative phenotypic correlation with grain yield and harvest index. This also adds to the fact that very tall and very late plants should not be selected. The result of the genotypic path coefficient analysis is very similar to the result of phenotypic path coefficient analysis, the correlation between the two being $0.99 * *$.

Table 3. Phenotypic direct (boldface and diagonal) and indirect effects on grain yield pot ${ }^{-1}$ in 49 tef genotypes tested under acid soil.

\begin{tabular}{lrrrrrr}
\hline & \multicolumn{1}{c}{ DTH } & DTM & \multicolumn{1}{c}{ PH } & \multicolumn{1}{c}{ SBM } & \multicolumn{1}{c}{ HI } & \multicolumn{1}{c}{$\mathbf{r}_{\mathbf{p}}$} \\
\hline DTH & $\mathbf{- 0 . 0 2 7 2}$ & 0.0156 & 0.0171 & 0.0443 & -0.3419 & $-0.3^{*}$ \\
DTM & -0.0143 & $\mathbf{0 . 0 2 9 6}$ & 0.0112 & -0.0915 & -0.3681 & $-0.43^{* *}$ \\
PH & -0.0148 & 0.0105 & $\mathbf{0 . 0 3 1 5}$ & 0.0378 & -0.1854 & -0.12 \\
SBM & -0.0033 & -0.0075 & 0.0033 & $\mathbf{0 . 3 6 3 6}$ & 0.0743 & $0.43^{* *}$ \\
HI & 0.0103 & -0.0120 & -0.0064 & 0.0297 & $\mathbf{0 . 9 0 8 3}$ & $0.93^{* *}$ \\
\hline
\end{tabular}

Residual value $0.008 ; *, * *$ : significant at 5 and $1 \%$ of probability level, respectively, DTH: days to heading, DTM: days to maturity, PH: plant height, SBM: shoot biomass, HI: harvest index, $\mathrm{r}_{\mathrm{p}}$ : phenotypic

Under lime treated soil conditions, the residual value of 0.014 at phenotypic indicated that the model explained 98.6\% (0.986) of the variability on grain yield. Four traits (PDUL, SBM, HI, and PPB) affected grain yield under this soil condition. The strong positive direct effect on grain yield was found from the harvest index (0.96) and shoot biomass (0.34). Selecting genotypes for higher HI together with higher SBM would be beneficial. Similarly, the genotypic path coefficient indicated that harvest index (1.0073) followed by shoot biomass (0.256), and peduncle length (0.066) exerted a positive direct effect on grain yield (Table 5). These traits had a positive genotypic correlation with grain yield ( $r_{g}$ from 0.01 to 0.96 ). The number of primary panicle branches (PPB) had 
a negative direct effect in grain yield, but weak positive genotypic correlation $\left(r_{g}=0.01\right)$ with it. The selection of traits that had a positive direct effect on grain yield can enhance it under this condition. This implies the selection of genotypes with moderate shoot biomass, relatively long peduncle length, and high harvest index with relatively low primary panicle branches would contribute to high yield under limed soil condition.

In agreement with these results, Chekole et al. (2016) reported that shoot biomass (0.928) and harvest index (0.739) exerted a positive direct effect on grain yield. Similarly, Abel et al. (2013) observed that harvest index (0.734) and shoot biomass (0.43) had a positive direct effect on grain yield of tef genotypes tested at Debrezeit. Dagnachew and Mengistu (2014) reported also the positive strong direct effect of harvest index (0.548) on grain yield.

Table 4. Phenotypic direct (boldface and diagonal) and indirect effects on grain yield pot $^{-1}$ in 49 tef genotypes tested under limed soil.

\begin{tabular}{llllll}
\hline Traits & PDUL & SBM & HI & PPB & $\mathbf{r}_{\mathbf{p}}$ \\
\hline PDUL & $\mathbf{0 . 0 3 8 2}$ & 0.0478 & 0.1059 & -0.0149 & 0.18 \\
SBM & 0.0054 & $\mathbf{0 . 3 3 8 8}$ & -0.0771 & 0.0024 & $0.27^{*}$ \\
HI & 0.0042 & -0.0273 & $\mathbf{0 . 9 5 5 7}$ & -0.0025 & $0.93 *$ \\
PPB & 0.0164 & -0.0231 & 0.0680 & $\mathbf{- 0 . 0 3 4 7}$ & 0.03 \\
\hline
\end{tabular}

Residual $0.014 ;{ }^{*}, * *$ : significant at 5 and $1 \%$ of probability level, respectively, PDUL: peduncle length, SBM: shoot biomass, HI: harvest index, PPB: primary panicle branches, $\mathrm{r}_{\mathrm{p}}$ : phenotypic correlation coefficient.

Table 5. Genotypic direct (boldface and diagonal) and indirect effects on grain yield pot ${ }^{-1}$ in 49 tef genotypes tested under lime treated soil.

\begin{tabular}{llllll}
\hline & PDUL & SBM & HI & PPB & $\mathbf{r}_{\mathbf{g}}$ \\
\hline PDUL & $\mathbf{0 . 0 6 6 2}$ & 0.0369 & 0.1338 & -0.0313 & 0.2 \\
SBM & 0.0095 & $\mathbf{0 . 2 5 7 0}$ & -0.2221 & 0.0077 & 0.052 \\
HI & 0.0088 & -0.0567 & $\mathbf{1 . 0 0 7 3}$ & -0.0044 & $0.96^{* *}$ \\
PPB & 0.0333 & -0.0316 & 0.0706 & $\mathbf{- 0 . 0 6 2 2}$ & 0.01 \\
\hline
\end{tabular}

Residual $0.012 ; * * *$ : significant at 5 and $1 \%$ of probability level, respectively, PDUL: peduncle length, SBM: shoot biomass, HI: harvest index, PPB: primary panicle branches, $r_{\mathrm{g}}$ : genotypic correlation coefficient.

\section{CONCLUSIONS}

Grain yield showed a strong positive correlation with harvest index, the yield of primary panicle and panicle weight which indicates improvements of these traits can contribute to the high grain yield of tef, while it was negatively correlated with days to heading and maturity under both soil conditions which suggests that selection for early genotypes with higher yield would be possible. Path coefficient analysis revealed that shoot biomass and harvest index had a positive strong direct effect on grain yield in both the conditions. However, both shoot biomass and harvest index had also contributed indirectly via peduncle length, suggesting that weightage should be given to these traits while selecting genotypes for higher yield.

\section{REFERENCES}

Abel D., Singh H. \& Hailu T. Interrelationship and path coefficient analysis of yield components in f-4 progenies of tef (Eragrostis tef). Pakistan Journal of Biological Sciences, 2013; 17: 92-97.

Bruce R. H. Soil testing handbook for professionals in agriculture, horticulture, nutrient and residuals management. $3^{\text {rd }}$ edition. University of Maine. pp. 27. 1997.

Chekole N., Wassu M. \& Tebkew D. Genetic variation, correlation and path coefficient analysis in Tef [Eragrostis Tef(Zucc.) Trotter] genotypes for yield, yield related traits at Maysiye, Northern Ethiopia. American Journal of Research Communication, 2016; 4: 73-102.

CSA. Agricultural Sample Survey Statistical Bulletin I. Report on area and production of major crops. Addis Ababa, Ethiopia: Central Statistical Agency. pp 53. 2018.

Dagnachew L. \& Mengistu G. Correlation and Path Coefficient Analysis of Quantitative Traits in Tef [Eragrostis tef (Zucc.) Trotter] Germplasm Accessions from Different Regions of Ethiopia. American Journal of Research Communication, 2014; 2: 194-204.

Dewey D. R. \& Lu K. H. A correlation and path coefficient analysis of components of crested wheat grass seed production. Agronomy Journal, 1959; 51: 515-518.

Eswaran H., Reich P. \& Beinroth F. Global distribution of soils with acidity. In: A.Z. Moniz, R.E. Schaffert, N.K. Fageria, C.A. Rosolem and H. Cantarella (eds). Plant-Soil Interactions at Low pH. Brazilian Soil Science Society, Viḉosa, Brazil. pp. 159-164. 1997.

Haftamu H. Interrelationship and Path Analysis of Yield Components in Tef [Eragrostis tef) Zucc. Trotter] Genotypes at Axum Northern Ethiopia. Journal of Biology, Agriculture and Healthcare, 2015; 5: 106-112. 
Johanson H. W., Robinson H. F. \& Comstok R. E. Estimates of genetic and environmental variability in Soybeans. Agronomy Journal, 1955; 47: 314-318.

Kebebew A., Hailu T. \& Arnulf M. Variation and inter-relationships of quantitative traits in tef (Eragrostis tef (Zucc.) Trotter) germplasm from western and southern Ethiopia. Hereditas, 2002; 136: 116-125.

Melak-Hail M. Chemical composition of Teff (Eragrostis tef) compared with that of wheat, barley and grain sorghum. Econ. Bot, 1966; 19: 268-273.

Mizan T. A., Shimelis H., Mark L. \& Kebebew A. Genetic variation and trait association of tef [Eragrostis tef (Zucc.) Trotter] evaluated under optimal and moisture stressed environments. Australian Journal of Crop Science, 2017; 11: 241-247.

Pavan R., H. C. Lohithaswa, M. C. Wali, Prakash G. \& Shekara B. G. Correlation and path coefficient analysis of grain yield and yield contributing traits in single cross hybrids of maize (Zea mays L.). Electronic Journal of Plant Breeding, 2011; 2: 253-257.

Plaza-Wüthrich S., Gina C. \& Zerihun T. Genetic and phenotypic diversity in selected genotypes of tef [Eragrostis tef (Zucc.) Trotter. African Journal of Agricultural Research, 2013; 8: 1041-1049.

Robertson G. E. The sampling variance of the genetic correlation coefficient. Biometrics, 1959; 15: 469-485.

Roseberg R. J., Norberg S., Smith J., Charlton B., Rykbost K. \& Shock C. Yield and quality of tef forage as a function of varying rates of applied irrigation and nitrogen. Research in the Klamath Basin, Annual report. 2005.

Seyfu K. 1997. Tef, Eragrostis tef (Zucc.) Trotter: Promoting the conservation and use of underutilized and neglected crops. International Plant Genetic Resources Institute, Rome, Italy.

Solomon C., Hailu T. \& Harjit-Singh. Genetic variability, heritability and trait relationships in recombinant inbred lines of Tef [Eragrostis tef(Zucc.) Trotter]. Research Journal of Agriculture and Biological Sciences, 2009; 5: 474-479.

Spaenij Dekking L., Kooy Winkelaar Y. \& Koning F. The Ethiopian cereal tef in celiac disease. New England Journal of Medecine, 2005; 353: 1748-1749.

Stallknecht G. F. "New Crop Fact Sheet: Teff ". Center for New Crops and Plant Products, Purdue University, West Lafayette. 1997.

Wondewosen S., Alemayehu B. \& Hussen M. Genetic variation for grain yield and yield related traits in Tef [Eragrostis tef (Zucc.)Trotter] under moisture stress and non-stress environments. American Journal of Plant Science, 2012; 3: 1041-1046. 